\title{
Teacher Preparedness to Utilize Emergent Literacy for Teaching Initial Literacy in Selected Schools of Mansa District
}

\author{
Samuel Imange ${ }^{a *}$ and John Simwinga, ${ }^{b}$ Ph.D. \\ ${ }^{a}$ Mansa College of Education, P.O. Box 710391, Mansa, Zambia \\ ${ }^{b}$ Department of Literature and Languages, UNZA, P. O. Box 32379, Lusaka, \\ Zambia.
}

"Corresponding author: Email address: $\underline{\text { samuelimange@yahoo.co.uk }}$

\begin{abstract}
Effective teaching of initial literacy in Grade 1 demands more of the teacher's attention to pupils' emergent literacy skills and consideration of how they learn. The emergent literacy skills children acquire lay a firm foundation for their learning to read and write in the conventional sense. Some of the skills that children develop under emergent literacy include phonological awareness and phonological sensitivity, which give children the ability to hear, recognize, manipulate and distinguish the sounds of the language they have acquired. These are key language skills which teachers will need to utilize in their teaching of reading and writing skills to Grade 1 learners in the classroom.
\end{abstract}

A study was carried out whose purpose was to investigate whether primary school teachers in Mansa District utilized emergent literacy skills in their teaching of conventional reading and writing skills to the learners in Grade 1 considering the fact that emergent literacy lays a firm and solid foundation for continuous development of the literacy skills. The study was a descriptive survey and qualitative in nature since it required the researcher to describe the state of affairs as found and observed in their natural setting in the research sites. The qualitative methods of data collection and analysis were used. The sample for this study comprised 62 Grade 1 teachers and 3,594 Grade 1 primary school pupils. Only those schools teaching initial literacy in the local familiar language using the Breakthrough to Literacy (BTL) methodology were targeted for this research.

The findings indicated that: (1) Teachers lacked knowledge about emergent literacy and did not know how useful it was for continuous literacy development among the children. (2) Most of the teachers ignored pupils' prior literacy knowledge and considered their learners as complete illiterates who knew nothing about literacy skills. (3) Teachers never designed extra teaching and learning materials for teaching literacy. Rather, they relied on the New Breakthrough to Literacy (NBTL) kit materials. (4) The class sizes were large and meaningful scaffolding was lacking in most of the classes.

This study concluded that the Ministry of Education in Zambia should consider emergent literacy as the foundation for conventional literacy development in Grade 1. One recommendation was that teachers should be equipped with knowledge of emergent literacy through deliberate training. They need to understand and appreciate emergent literacy as an essential body of knowledge to be utilized for successful conventional literacy development among Grade 1 learners. 


\section{INTRODUCTION}

Marie Clay introduced the concept 'emergent literacy' in 1966 as a term referring to skills children develop from birth to the time just before their entry into the formal school system. Since then, it seems to have received more attention in the Western World countries. More studies have been conducted in America and some European countries with a view to develop clearer understanding of Clay's concept of emergent literacy. Other researchers have said that emergent literacy describes the behaviours exhibited by young children who cannot actually read and write in the conventional sense but use books and writing materials to imitate reading and writing activities they observe from the adult world. Another common explanation says emergent literacy refers to the behaviours young children portray as a way of reflecting their understanding of the reading and writing activities that they experience even when they are not readers and writers themselves.

Studies from European countries show that emergent literacy involves development of skills, knowledge and attitudes which at a later stage play a significant role in the development of reading and writing skills in children. Some of the skills that develop under emergent literacy include phonological awareness and phonological sensitivity, which give children the ability to hear, recognize, manipulate and distinguish the sounds of the language they have acquired. The emergent literacy skills children have acquired lay the foundation for them to learn to read and write in the conventional sense. These are key language skills which teachers should utilize in the classroom while teaching of reading and writing skills. Other literacy behaviours that teachers with knowledge of emergent literacy should look out for in children involve activities such as children talking about their families, telling or narrating stories while interacting with each other, holding books right side-up, doing pretend reading and pretend writing, flipping pages of books and interpreting pictures in books. These are taught as pre-reading skills but are not treated as possible literacy foundational skills children have before they come to school. The expectation is that Grade 1 teachers in Zambia should take advantage of such skills in their children as the foundation for teaching them conventional literacy.

\section{STATEMENT OF THE PROBLEM}

While a number of studies have highlighted a number of classroom factors that underlie the low literacy levels among Zambian children, little is known on the extent to which Grade 1 teachers utilize emergent literacy to enhance literacy development in children. The importance of emergent literacy as a firm foundation for conventional literacy development cannot be underscored, however, there is no empirical evidence in Zambia on the preparedness of Grade 1 teachers to utilize emergent literacy. Therefore, this study was designed to investigate teachers' utilization of emergent literacy in teaching conventional reading and writing skills, a procedure that would enhance continued development of conventional literacy in children at Grade 1.

\section{PURPOSE OF THE STUDY}

The purpose of this study was to establish whether primary school teachers utilize emergent literacy skills in order to teach the learners the conventional reading and writing skills. 


\section{OBJECTIVES}

The study sought to achieve the following objectives:

Establish what primary school teachers know about emergent literacy.

Determine whether or not primary school teachers utilize emergent literacy skills for teaching learners to read and write.

Establish what extra teaching and learning materials teachers design to help utilize emergent literacy for teaching learners to read and write.

Establish the challenges Grade 1 teachers encounter in utilizing emergent literacy.

\section{MAIN RESEARCH QUESTION}

The main research question was: Do the primary school teachers utilize the emergent literacy skills learners come with from home to school to learn to read and write?

\section{RESEARCH QUESTIONS}

What do primary school teachers know about emergent literacy?

How do teachers utilize emergent literacy skills when teaching reading and writing?

What extra teaching and learning materials are designed to help in utilization of emergent literacy for teaching learners to read and write?

What challenges do Grade 1 teachers encounter in utilizing emergent literacy among the Grade 1 learners?

\section{SIGNIFICANCE OF THE STUDY}

This study sought to investigate the teacher's ability to utilize learner's emergent literacy skills in the teaching of conventional literacy in Grade 1. Exploitation and utilization of emergent literacy may be of benefit to the learners by offering them chance for a continuous literacy development when they enter the formal school system from the emergent literacy period. The results of the study may provide relevant information on the need to design a literacy programme to empower the teachers with information on emergent literacy, which may serve as an intervention to low literacy achievements scored by the learners in schools. In addition, the results may also influence a review and change of the teacher education curriculum for colleges of education in Zambia to include emergent literacy component. The results from this study might as well influence further research regarding classroom utilization of emergent literacy skills as the foundational information for literacy instruction in the formal school set up.

\section{METHODOLOGY}

\section{Area of study}

The study was conducted in Zambia's Luapula Province, Mansa district in particular. The sample for this study was drawn from the primary schools within the district. The study targeted those schools offering initial literacy to Grade 1 learners in a local language because it is in the local language that children have their experiences. Most of their emergent literacy skills were acquired through the familiar local language. 


\section{Research design}

Research design shows the planned outline (or the scheme of the research) which the researcher opted to use to generate answers to the research problems identified. This study employed the qualitative approach to establish what primary school teachers knew about emergent literacy and to establish whether they utilized this knowledge during teaching of reading and writing skills to Grade 1 learners. This study was a descriptive survey one and qualitative in nature since it required the researcher to describe the state of affairs as found and observed in their natural setting in the research sites. Orodho (2003, cited in Kombo \& Tromp, 2009), says descriptive survey is a method of collecting information by interviewing or administering a questionnaire to a sample of individuals.

\section{Target Population}

In research, a population is a group of individuals with at least one or more characteristics, which distinguish that group from the rest of individuals and the group should be of interest to the researcher (Best \& Kahn, 2006). For this research, the targeted population consisted of all Grade 1 classes and their teachers in Mansa District. This group was targeted as the main source of information the researcher intended to collect.

\section{Sample and sampling techniques}

A sample is a portion of the elements in a population (White, 2005). A sample of sixty-two (62) Grade 1 teachers and 3,594 pupils from thirty-two (32) primary schools were selected as respondents and sources of the required information. All the schools were selected from within Mansa District. Ten (10) of the schools were located in Mansa town and twenty-two (22) of them were from the outskirts. The targeted schools were those that offer initial literacy lessons using the New Breakthrough to Literacy (NBTL) methodology, and those that were easily accessible by motor transport. The sampling technique was based entirely on this judgement by the researcher. Purposive sampling technique was employed in order to select the sample for the research. Sampling means making a selection from the population frame in order to identify the people or issues to be respondents or sources of information for the research (White, 2005).

\section{Research instruments}

A structured observation guide and a semi-structured standardized interview guide were the instruments used to collect data through lesson observations and post-lesson interview with each teacher observed. The structured observation instrument was used to check classroom practices pertaining to teacher utilization of the emergent literacy knowledge learners may have acquired from birth up to the time they were enrolled in Grade 1 . The instrument was also used to check for extra teaching and learning materials the teachers were using for teaching initial literacy to Grade 1 learners, which would trigger learners' experiences in the process of learning to read and write. The written questions in the semistructured interview guide were of great use when interviewing the grade 1 teachers about what they knew of emergent literacy. The focus of the interview was on whether teachers use this knowledge from among the learners during teaching of conventional literacy. The interview also aimed at finding out whether teachers knew how important emergent 
literacy was as a foundational resource for the learners in their learning to read and write in the classroom situation.

\section{Data collection}

The data were collected in two (2) ways and these were lesson observation and post-lesson interview with each teacher observed. The first step in data collection was conducting lesson observations of the actual literacy lessons being taught by each of the teachers, using the observation checklist instrument. The teacher was allowed to teach his or her lesson normally while the researcher sat at the back of the class quietly taking complete and descriptive field notes of the observations he was looking out for in the lesson using a pre-designed lesson observation guide. Some of the emergent literacy practices looked out for in the lessons included pupil's knowledge of how to hold and use various writing tools, teacher-initiated scribbling, drawing, and copying or writing activities. Learners' holding of storybooks right side up, teacher instruction on flipping of pages from left to the write, varied picture reading exercises initiated by the teacher, and other classroom activities related children's to pretend reading.

The second step in data collection involved the researcher carrying out the face-to-face interview with each one of the teachers observed using the designed interview guide. According to Tuckman (as cited in Cohen and Manion (1981: 243), an interview "provides access to what is inside a person's head, makes it possible to measure what a person knows (knowledge or information), what a person likes or dislikes (values and preferences) and what a person thinks (attitudes and beliefs)." The focus of the interview was on teachers' knowledge and their perspective on emergent literacy. The main aim was to find out how much teachers of conventional literacy in Grade 1 knew about emergent literacy and if at all, they utilized this knowledge from among their learners while teaching them to read and write under the established New Breakthrough to Literacy methodology.

\section{Data analysis}

Data collected in the study were analyzed qualitatively under various themes derived from the objectives of the study. Data collected were identified and organized into categories in relation to research objectives and questions for the research. The data analysis involved description, explanation and interpretation of the observations made and responses collected from the interview. It was mainly a descriptive analysis of data.

\section{RESULTS AND DISCUSSION}

The presentation and discussion of findings have been combined based on the pertinent areas of focus of the study. Specifically, the paper highlights among other issues Grade 1 teachers' knowledge of emergent literacy and the findings on whether utilization of emergent literacy skills as a foundational resource for teaching conventional reading and writing skills takes place in Grade 1. The paper also highlights on the designing of extra teaching and learning materials to facilitate utilization of emergent literacy and the challenges teachers experience in the possible utilization of emergent literacy for teaching the conventional reading and writing skills among Grade 1 learners. 


\section{Primary school teachers' Knowledge of Emergent literacy}

The findings from the study have shown that none of the sixty-two (62) Grade 1 teachers observed and interviewed had an idea about emergent literacy. None of them was able to answer the question that focused on the importance of emergent literacy in class during teaching and learning of initial literacy. It was equally difficult for all the respondents to cite examples on how they utilized emergent literacy knowledge from among the learners in their teaching sessions. Neither, could they state the problems they encountered nor experienced in their efforts to utilize emergent literacy for continuous literacy development among their learners.

On the question about how teachers value or consider children's previous experiences during literacy lessons, most of the teachers stated that learners come to school in Grade 1 without knowing anything, especially if they had not been to nursery school. One common comment to the question was that learner's background was unreliable because they had not been to preschool.

"I have to begin from the scratch", one teacher said. An additional comment was that, "It is quite difficult to organize the learners since everything is new to them." It was further stated that, "We take children as coming from unknown backgrounds, and this does not matter, the teacher has to begin everything with them right from the base." From the teachers' observation, "Preschool learners did much better than those who came direct from home." However, another respondent reported that the learners in her class from preschool found problems with the local language. Only one teacher gave a contrary comment based on her experience that, "It is important to use learners' environmental background to teach them to write what they say." The teacher further stated that this was achieved by asking learners to talk about their homes in relation to the literacy lesson for that day. Though this was the response, there was no activity in her lesson that depicted the aspect to do with learners' background.

A related response from another teacher was that, "The language children used at home was the same language we use for teaching them literacy." It was exemplified that the use of a local language helps learners to participate and interact freely during lessons and learners capture information quickly. Oral language, which is a component emergent literacy, is the basis for teaching learners the literacy skills. One other common response from most teachers was that traditional songs and storytelling are helpful and valuable during literacy lessons. Contrary to the above information was the response that, "Children's background does not matter in the teaching of literacy because learners come from different homes with various backgrounds." The emphasis was that children come to school without any literacy. While some children showed interest to learn, it was completely the opposite with other learners. The feeling of many teachers was that they needed to encourage, or force the children to begin learning from the scratch.

Analysis of the data collected showed that none of the sixty-two (62) Grade 1 teachers observed and interviewed knew what emergent literacy was. Neither did they know how useful emergent literacy was for teaching children the conventional reading and writing skills on a continuum model. Their inability to answer any question that dealt with the 
emergent literacy concept was a clear indication that the teachers did not have an adequate understanding of this concept. This implied that teachers lack knowledge of emergent literacy skills, which is children's most useful foundational knowledge in the classroom set up for teaching them the reading and writing skills. Another implication was that emergent literacy was a new concept to all the teachers this research interacted with.

\section{Grade 1 Teachers' Utilization of Emergent Literacy}

The second objective of this study was to establish whether or not teachers were utilizing learners' emergent literacy skills in teaching Grade 1 learners the essential skills of reading and writing. In attempting to address the demands of the second objective, it was important to bear in mind the fact that spoken language is the starting point for literacy development. This area was important for the researcher to investigate as to how much of the emergent literacy embedded in oral language was used by the teacher. Oral language activities in a literacy lesson were very important for the researcher because they were to reveal what emergent literacy skills the sampled learners possessed. The expectation was that the richer the oral vocabulary learners exhibited, the more emergent literacy there was in the learners for the teacher to make use of in his/her teaching of reading and writing skills. It was established that most of the teachers did not prepare any oral language activities that required learners to interpret the meanings of the stories read or narrated, or relating the stories to real life situations at home. Only nine (9) teachers asked their learners to relate the stories they had heard to their own situations.

There were no other activities or tasks teachers prepared for learners meant to exploit further the stories they had heard through reading or narration. Learners hardly talked about their families. This was where the teacher would have explored most of the emergent literacy in pupils. They never engaged in further conversations that would help them (teachers) learn or realise the usefulness of stories that were read or narrated in class. Learners never engaged in any activities that would have helped develop their memory and broaden their attention span and as a way of making them more involved in learning activities. None of the teachers involved learners in oral language-based activities as a means to improve speaking and listening skills. What was lacking was provision of meaningful context and concrete experiences for learners to use language and integrate opportunities to read, write, speak and listen. Such are the skills that emerge from emergent literacy.

The pattern was the same with how the literacy behaviours of pretend reading and pretend writing from emergent literacy point of view were handled by the teachers. There were limited reading opportunities provided for the learners, and there were no other tasks based on reading materials provided for the learners other than those designed in the New Breakthrough to Literacy kit materials. If more activities to do with storybooks were generated in the sampled classes, the 'pretend reading' component of emergent literacy could have exposed the precursor knowledge to reading and writing. Equally, 'pretend writing' activities, which learners exhibit, are products of emergent literacy. The researcher looked out for such activities among the sampled learners to see how the teacher was going to build the conventional writing skills among the learners from the emergent literacy point of view. The activities given were based mainly on the pre-reading and pre-writing skills 
introduced at 'Starting Together'. Apparently, this is the stage at which aspects of emergent literacy are supposed to come out from among the learners and where the teacher is expected to begin scaffolding procedures for literacy development.

This study also established that right from the early stages of formal learning, learners received little attention to help them develop skills of legible writing. Though a variety of writing activities such as handwriting, picture drawing, and copying exercises were given to the learners, little interest was shown from the Grade 1 teachers to assist their learners develop appropriate writing skills. There were no instructions issued to the learners concerning correct usage of pencils as writing tools. Some learners held pencils at the writing tip and applied saliva to the writing tip by dipping it in their mouths before they wrote down any single letter in their exercise books. Advice on skipping of pages was rare and some teachers laboured and wrote down the day's date in the learners' exercise books as a way of showing them where to write new work for that day. These findings show that the respondents did not adequately utilize the emergent writing skills portrayed by the learners for purposes of teaching and developing conventional literacy skills in them on a continuum model. One major implication from these findings is that children's emergent writing skills remain underutilized thereby not achieving the intended legible writing skills looked out for among our learners. This observation is in line with Korat (2005) who maintains that children's emergent literacy knowledge of written language helps them in understanding the conventions of print.

This study established that most of the teachers regarded their children as not knowledgeable about anything to do with reading and writing. The teachers ignored most of the prior knowledge (see Whitehurst \& Lonigan, 1998) to formal reading and writing which learners acquired before entry into Grade 1. They judged their learners as mere beginners who did not know anything about such literacy skills as holding books right side up, identifying 'print' on a page and that they were without any early writing development such as scribbles. The findings are in line with Musonda's (2011: 5) report that, "It is common in most Zambian schools to find children in Grade 1 being treated as complete illiterates." The findings of this study imply that children's emergent literacy which greatly affects their abilities to learn, remember, reason, solve problems, and acquire new knowledge from their classroom or learning environment is not appreciated by their teachers and therefore, not utilized for the benefit of conventional literacy learning. The prior knowledge to reading and writing which children come with into the classroom is the emergent literacy (the foundational skills) that teachers must make use of in scaffolding learners to conventional literacy development. However, teachers teach everything because they think pupils do not know anything. They ignore the emergent literacy children have already.

The implication is that teachers do not adequately guide their learners during literacy lessons to locate the knowledge that children themselves learnt earlier at home through social context so that they apply it to learn new skills such as reading and writing. For this reason, much of the learners' potential is not stimulated in the direction towards helping the learners to actively seek new information in the process of learning. Further implication from this is that the range of prior knowledge, skills, beliefs, and concepts that significantly influence what learners notice about the environment and how they organize 
and interpret it, as stated by the National Academic Press (2000), will not be fully functional in the learning process provided in the classroom. The findings evidently show that teachers lack conscious utilization of the emergent literacy learners come with into Grade 1. Teachers are not aware about the emergent literacy concept.

Further findings of this study were that limited foundational listening and speaking skills activities necessary for literacy development were generated for learners in the classrooms where this research was conducted. For example, the few classroom stories that were either read or narrated were not exploited any further for the benefit of children learning new language skills related to literacy development. Learners hardly engaged in conversations and hardly talked about their families as a way of relating the stories they heard to real life situations. The implication of their approach to teaching is that it works against what Gable (n.d.) (http://missourifamilies.org/features/childcarearticles/childcare3.htm) stated that to promote young children's delight in talking, listening, reading and writing, adults need to provide a variety of interesting language experiences. The language experiences can only come from children's emergent literacy. Because teachers do not adequately scaffold the learning process, a child's reading difficulties in the primary grades will not be alleviated by the learning experiences they undergo. This is because the link between children's emergent literacy and the new knowledge to be learnt is missing.

The other finding from this study was that though the NBTL methodology provides room for the teacher to improvise during lesson delivery, most of the teachers did not go beyond the proposed teaching methodologies as a means to broaden their teaching styles. This implied that the limited language activities that teachers planned for their learners in most of the classrooms did not provide a broader base which Vygotsky (1978) calls the cultural tools for learning, from which meaningful learning of reading and writing skills would have been achieved on a continuum model.

One possible effect from this inadequacy of classroom oral language activities will be that the process of learning to read and write will not be holistic and meaningful without involving the child's experience of spoken language, which is a component of emergent literacy. One implication is that the role of vocabulary during initial literacy learning should be recognized because it is already part of children's vocabulary and that is what they need to make sense of in print (Dickinson \& Neuman, 2006). The reason is that it is through the spoken language that children acquire the knowledge of how sounds of the language operate, how the words are formed and relate to each other, how they are pronounced, how language conveys meaning and how members of the community achieve their goals using language, as supported by Halle, et al. (2003). The other implication is that, if not generated under learning activities, this essential knowledge acquired through spoken language will not apply in the classroom situation as children learn to read and write. Meaningful classroom learning will only take place if a link is generated between the old and new information.

This research further established that teachers hardly gave learners independent tasks that required learners to use the storybooks from the library corner to thoroughly explore and interpret stories from the pictures in the books. Given overwhelming evidence about 
children's home experiences, the researcher argues that pupils come to school with a lot of stories which teachers can develop into cards or brochures and use them to enhance literacy development other than relying on the limited stories in the kits. Where teachers manage to use pupil-generated stories thoroughly to the advantage of the learners, the practice would acknowledge Morrow's (1995) argument that environmental print is of no use to the child if no adult brings the child's attention to it. This study also established that despite the confirmation from some teachers that most learners preferred books with pictures in them, teachers still relied on the limited activities of utilizing the knowledge they observed from amongst their learners. As a way to scaffold the development of conventional reading skills among Grade 1 learners, teachers need a variety of resources that are pupil-generated for them to teach reading and writing skills meaningfully based on the theory of teaching from the known to unknown. The implication arising from this inability is that learners in the classroom were deprived of an opportunity to freely interact using their own stories to stimulate their minds for learning. If only the teachers initiated such activities to make pupils' minds ready to adapt and accommodate new information as proposed by Piaget (1969), thereby fulfilling the approach of learning from the known to unknown (Bruner, 1974).

The most common picture-reading activity teachers set for their learners was the one that required the teacher and the learners to elicit the key sentence from the 'conversation poster', as established in the daily lesson routine. The only major reading task that required learners to read the key sentence that the teacher wrote on the chalkboard was not sufficient to stimulate effective learning among the learners. The theoretical implication is that the absence of guided literacy practices will not spearhead literacy development as observed by Bodrova and Leong (2001) when they talk about shaped children's learning. In this case, limited reading tasks and opportunities were provided from which learners would independently learn the conventional literacy skills using the available reading materials provided under the Breakthrough to Literacy kit. In order to develop new skills in children, teachers must work alongside them in modeling and guiding their learning (Evans, 2001 as cited in Hodgskiss, 2007).

\section{Designing of Extra Teaching/Learning Materials to facilitate Utilization of Emergent Literacy}

The study revealed that teachers did not design extra teaching and learning materials that had an emergent literacy background in them for literacy teaching. During the research period, none of the teachers observed used other extra teaching and learning materials that were to reactivate children's emergent literacy during the initial literacy lessons. All the teachers relied on the teaching and learning materials provided for the New Breakthrough to Literacy Kit. Where the New Breakthrough to Literacy kit materials were not available, as was the case with four schools, teachers either drew similar posters like those in the kit or rather borrowed similar materials from the neighbouring schools. The finding was that teachers exclusively relied on the New Breakthrough to Literacy kit materials for teaching reading and writing skills.

One implication drawn here is that there were limitations of classroom opportunities from which teachers were to explore a variety of emergent literacy practices from among their 
learners. Scaffolding through using extra teaching and learning materials would help learners easily and quickly grasp conventional literacy skills in the literacy classrooms. This observation is in line with Vacca, et al (1991) who maintain that children's literacy develops through active engagement with their world in purposive and real-life settings. An underlying assumption drawn from this study is that designing and using appropriate extra teaching materials with emergent literacy background may stimulate and broaden the chances of utilizing the essential prior knowledge to reading and writing that learners earlier acquired from their homes and pre-school environment.

The other implication observed, as supported by Ministry of Education, Science, Vocational Training and Early Education (1992) document, is that learners cannot attain relatively satisfactory levels of learning and achievement in the absence of appropriate learning materials. Provision and appropriate usage of the learning materials enhances learners' cognitive achievement. This statement is in line with Johnston's (2005) idea saying new language tools mean new opportunities for social understanding, for learning about the world, and for sharing experiences, pleasures and needs. The findings from this study further imply that lack of provision of relevant and appropriate learning resources, especially in literacy classes, will not cater for children who lack these materials in their homes and even the wider society. The findings further imply that the relative abundance of reading books, writing materials, and other varied educational aids of various kinds will set the quality of an education system that will produce an efficient reader and writer into the Zambian society. The learning materials will help the teachers to utilize the learners' experiences for grasping new information offered by the teacher in the literacy classroom environment.

This study also established that even in classrooms where teaching and learning materials were available, teachers restricted learner's usage of such materials. Though guided learning is important at this stage, as suggested by Vygotsky (1978), the implication of using learning materials in such a manner in literacy classrooms in particular, limits learners' opportunity to interact and freely use the materials for learning purposes. The researcher argues that where freedom of participation in a learning environment is restricted, development towards personal responsibility and educational growth is restricted as well. As supported by Zygouris-Coe (2001), teachers lack skills of creating literate environments in classrooms and children receive insufficient instructional support from the teaching and learning materials as a way to help them learn to read and write successfully.

\section{Challenges Grade 1 Teachers Encounter to Utilize Emergent Literacy}

The fourth objective of the study wished to establish the challenges that Grade 1 teachers encountered during literacy instruction. To establish these challenges, the researcher took into account the fact that current literacy instruction in schools comprised aspects of emergent literacy utilization though teachers themselves were not aware about it. The classroom oral language activities such as storytelling or narration, usage of books in the library corner, picture discussion, drawing and other writing activities, which follow the pre-reading and pre-writing activities, are good examples where teachers utilize some skills of emergent literacy. 
Given this scenario, this study established that over enrolment was one of the major challenges hampering the teaching of initial literacy. For example, 37 classes had between 50 and 135 pupils per class. The average enrolment of the 62 classes involved in the study stood at 58 learners per class. This challenge posed a number of problems for the teacher in the classroom. Most of the classes were found to be too large for the available fewer teaching and learning materials, which made it difficult for learners to breakthrough. Teachers found it extremely difficult to attend to individual learners and to monitor an individual child's progress in the lesson effectively. This research also found out that sometimes teachers experienced late enrolment of learners as well as enrolment of children below the age of five. Such children were found not to be mature enough or ready for instruction at Grade 1 level.

One contributing factor to this challenge stemmed from Ministry of Education, Science, Vocational Training and Early Education's enrolment policy that all eligible children be enrolled into Grade 1. The policy was implemented without intervention measures on the resultant large class sizes. For example, the teacher-pupil ratio had not been addressed. The implication of these findings, as supported by Cakmak (2009), are that large class sizes have a negative effect on classroom management, class motivation, teaching methods and strategies.

As observed, large classes tend to be noisy, control for effective learning becomes difficult and the teacher cannot afford individual attention to all the learners in class. The present study established that most of the teachers found it problematic to create, maintain quality relationships and motivate the learners in their classes. This was not workable in a class of over seventy-five (75) learners, where even the teacher lacked motivational drive. The findings imply that in the event where other classroom conditions were favourable for teaching and learning, if not addressed, large class sizes will still pose a challenge to teaching and learning processes and further hamper smooth literacy skills development in children. As Cakmak (2009) indicates, the requirement of knowing the individual child's characteristics and motivating them differently will not apply and that general pupil performance will remain remarkably low.

Where pedagogical issues were concerned, the current study established that implementation of learner-centered instructional procedures were not possible. Activity based learning strategies did not work in most of the classes and besides, the methods left greater room for memorization of reading words and sentences as most of the learners failed to read words in the absence of an accompanying picture. These findings are in line with the results of the study by Blatchford et al. (2003) cited in Cakmak (2009: 401) which state that, "children in large classes are more likely to be off task in terms of not attending to the teacher and not attending to their own work when on their own." The effect is that learners do not breakthrough to literacy and chances of developing a sense of creativity and self-confidence is completely lost.

Through the interviews, this research also established one unique but interesting challenge that concerned learners with Special Education Needs in two separate schools. Those interviewed in two separate schools shared their experiences about teaching literacy skills to children with Special Education Needs (SEN). The four learners in question were deaf 
and dumb. The two teachers confirmed that it was not easy for them to teach literacy skills to such children because they were not specialized to handle such cases. Because of their condition, the children were usually ignored and left unattended to by their teachers. The two teachers found it difficult to teach the dumb and deaf children who were combined with the so-called 'normal' children. Both teachers never received specialized training to handle learners with special education needs. As such, the children did not receive any language and literacy learning support from their teachers. The implication of the above challenge is that children with learning difficulties are denied their chances to achieve conventional literacy development according to their own pace of achievement if they were offered equal learning opportunities. This is even made worse where there is lack of a strong partnership between the school and parents towards their children in school. The challenged learners are often disadvantaged in as far as education provision is concerned.

Another challenge established by this study is that absenteeism also hindered progression of learners. Irregular attendance of lessons by learners negatively affected the progression of lessons because teachers were forced to repeat previous lessons in order to accommodate every pupil for new literacy lessons. This finding is closely related to another challenge that concerned pedagogical issues. The expectation from the researcher was that the teachers would make use of what the learners portrayed about literacy to teach them new things. Contrary to their theoretical praise about literacy teaching, most of the teachers expressed a concern that literacy teaching involved too many activities within one lesson. Another concern observed was the weaknesses of the current literacy teaching methodology. Teachers felt it encourages learners to read words through memorizing. The researcher's argument here is that the aspect of learning from memorization could have been solved had the teachers made use of pupils' emergent literacy to teach them the conventional literacy skills of reading and writing. Learners were going to find it interesting if they establish a link between what they experienced at home or pre-school to that taking place in the classroom. Another challenge the teachers expressed was that the routines were confusing and very difficult for learners to follow, especially at 'Stage 1'. Apparently, this is the stage of the lesson where emergent literacy skills could easily be identified. In addition, teachers complained that time was too limited to fully cover all the lesson stages successfully. Teachers who were not familiar with Icibemba confirmed it was difficult to teach initial literacy to children using a language the teachers did not know themselves. Generally, teachers believed there was no motivation for the Grade 1 teacher who worked so hard to make the illiterate child literate.

One very common challenge teachers emphasized about was lack of teaching and learning materials in their classes because the kit either wore out, was stolen or vandalized. In schools where there were more than one stream, sharing of the few teaching materials available in that school hampered lessons progress, especially if allocation of classes was within the same time. Though this was the situation, teachers never took advantage of the available resources to exploit what emergent literacy children come along with from their homes so that their teaching was based on what was known. Another compounding challenge to this one was that the fewer materials could not be allocated permanently to one classroom for learners to use for revision during their spare time. It was observed that learners had limited time to interact with teaching and learning materials. The situation did 
not leave enough room for teaching literacy only in one room. The common view from most of the teachers was that Grade 1 learners needed to have permanent rooms for easier storage and usage of materials. In addition, the class arrangement was usually disturbed because learners had to leave immediately to give room to other classes.

\section{Conclusion}

This study concludes that emergent literacy, a phenomenon dealing with the development of reading and writing skills in young children before their entry into formal school, deserves thorough and careful consideration by the education sector in Zambia. As supported by Strickland and Morrow (1988) and Hodgskiss (2007), the concept emergent literacy concerns the recognition that during their development stage, children acquire knowledge and skills that become very essential later for learning of formal reading and writing skills. The conclusion therefore is that teachers need to understand emergent literacy thoroughly as a body of knowledge to be utilized fully during the teaching of conventional literacy in the formal school set up. A further assumption from this study is that given adequate knowledge on emergent literacy, the Grade 1 teacher may make the classroom an environment that will promote and develop learners into more skilled readers and writers.

Teachers do not design other teaching and learning materials; neither do they bring to class other language materials for teaching reading and writing. The concept of teaching from the known to unknown is underutilized. Teachers rely on the pre-reading and pre-writing skills, which are just a part of emergent literacy, as a base from which to teach conventional reading and writing skills to children in Grade 1. Research also did establish that teachers rely only on the Breakthrough to literacy kit teaching and learning materials. They have ignored the concept of 'improvisation' in their teaching.

One of the major challenges that Grade 1 teachers encountered was the large pupil numbers in their classes, which made literacy class management and teaching extremely difficult for the teacher. The teacher-pupil ratio was still unaddressed since the enrolment policy was revised to enroll all eligible children into Grade 1. It was also found out that there was lack of a strong partnership between the school and parents towards the learning process for their children. Parents tended to leave everything to the teacher; they had nothing to do with their children at school.

The overall conclusion from this study is that teachers lack knowledge of the emergent literacy skills and are incapable of utilizing it for teaching new language skills of reading and writing in the formal school set up. Though this may be the case, the findings of this study cannot be generalized as applying to all the schools in the country since the research was only confined to some schools in only one district out of over seventy-two of them in the country.

\section{Recommendations}

This research recommends that the Government through the Ministry of Education, Science, Vocational Training and Early Education, the Teacher Education department reviews and redesigns the teacher-education curriculum to include a component on 
emergent literacy to ensure that teachers are equipped with emergent literacy skills through training. This may help teachers successfully offer literacy lessons on a continuum model and may help prepare teachers for explicit reading and writing instruction in Grade 1.

The Breakthrough to literacy methodology in Grade 1 be reinforced by revising the syllabus so that literacy instruction includes a component of exploration and utilization of emergent literacy skills among the Grade1 learners. This may maximize the concept of teaching from the known to the unknown. The process may influence improvement in pedagogical skills and other knowledge meant for efficient teaching of reading and writing skills among the Grade 1 learners.

The research further proposes to the Government that through the Ministry of Education, Science, Vocational Training and Early Education, considers the possibility of formulating a policy on offering nursery and preschool education to all children in Zambia before they enter Grade 1. This may help equip the children with the much needed background experience, or prior literacy knowledge, before they begin receiving literacy development instruction at formal school level.

The Ministry of Education, Science, Vocational Training and Early Education should create a print-rich and language-rich environment in the primary classroom that will reinforce the learners' awareness of the text. The Ministry should design learning centers that will encourage young children to engage in active exploration of their environment, and to talk and write about their learning experiences as a measure of enhancing literacy development in the children.

To improve the rate of development of literacy skills in Grade 1, the Government through the Ministry of Education, Science, Vocational Training and Early Education should consider supplying a variety of teaching and learning materials in form of talking storybooks and Information and Communications Technology (ICT). This way, teachers may help to scaffold their learners better and help them move from dependence to independence in the process of learning in the classroom.

This study recommends that in the absence of Special Education teachers, let the literacy teachers receive Special Education training to help in teaching learners at the risk of reading and writing failure, the hard-to-teach children and those with diverse needs.

\section{ACKNOWLEDGEMENTS}

I sincerely thank the following for their contribution, guidance and support rendered during the research: all the Grade 1 teachers and pupils who were respondents to my research, the Education Officers at Provincial and District levels for their encouragement. Special thanks to my supervisor and the core-author Dr. John Simwinga. I also extend special thanks to Dr. John R. Luangala the programme coordinator, all the staff in Language and social Sciences Department, and NOMA - who sponsored this research. 


\section{REFERENCES}

Barton, D. (2007). Literacy: An Introduction to the ecology of written language ( $\left.2^{\text {nd }} \mathrm{ed}\right)$. Malden, MA: Blackwell Publishing

Best, J. W. and Kahn, J. V. (2006). Research in education (10 ${ }^{\text {th }}$ ed.). New Delhi: PrenticeHall

Bodrova, E. and Leong, D. J. (2001). Tools of the Mind: A Case study of implementing the Vygotskian Approach in American Early Childhood and Primary Classrooms. IN NODATA MONOGRAPHS - 7 UNESCO. Geneva: International Bureau of Education. Sourced form: http://www.ibe.unesco.org/pdf

Bruner, J. S. (1960). The Process of Education. Cambridge, MA: Harvard University

Clay, Mary. 1966. "Emergent Reading Behaviour." University of Auckland: New

Zealand. Unpublished Ph.D. Thesis.

Cohen, L., Manion, L. and Morrison K. (2007). Research methods in education (6 $6^{\text {th }}$ ed.). New York: Routledge.

Dickinson, D. K. \& Neuman, S. B. (eds). (2006). Handbook of early literacy research Vol. 2. New York: The Guilford Press.

Hodgskiss, J. A. (2007). A Case study: Tracing the development of literacy in a Grade $R$ class. Rhodes University, S. A. Unpublished Masters Dissertation.

Korat, O. (2005). Contextual and non-contextual knowledge in emergent literacy development: A comparison between children from low SES and middle SE communities. DTD 5 Early Chidlhood Research Quarterly: Article in Press. Bar Ilan University, 52900 Ramat Gan: Elsevier Inc.

Matafwali, B. (2010). The Role of Oral Language in the Acquisition of Early Literacy skills: A case of Zambian Language and English. Lusaka: The University of Zambia. Unpublished PhD. Thesis

Ministry of Education, (1992). Focus on Learning: Strategies for the development of school education in Zambia. Lusaka: Ministry of Education, Science, Vocational Training and Early Education

Morrow, L. M. (ed) (1995) Family Literacy: Connections in Schools and Communities. New Jersey: Rutgers University.

Musonda, M-G. (2011). Literacy behaviours which pre-schoolers exhibit in selected households of Lusaka. Lusaka: The University of Zambia. Unpublished Dissertation.

National Academy Press (2000). How people learn: Brain, Mind, Experience and School. USA: National Academy Press. 
National Reading Panel (2000). Literacy Development. Retrieved on 1 May 2012 from the World Wide Web: http://www.netc.org/focus/Challenges/litercay.php

Santrock, J. W. (2002). Educational Psychology: second edition. New York: Mcgraw Hill Schunk, H. D. (2009). Learning theories; An educational perspective ( $5^{\text {th }}$ ed.). London; Pearson Education Limited.

Sénéchal, M. (2009). Literacy, language and emotional development. Rev ed. In Tremblay RE, Barr RG, Peters RDeV, Boivin, (eds.). Encyclopedia on Early Childhood Development [online]. Montreal, Quebec: Centre of Excellence for Early Childhood Development; 2009:1-6. Available at: http://www.childencyclopedia.com/documents/SenechalANGxp.pdf. Accessed 1 May 2012.

Slavin, R., E. (2009). Educational psychology: Theory and practice (9 $9^{\text {th }}$ ed.). New Jersey: Pearson Education, Inc.

Teale, W. and Sulzby, E. (1989). Emergent Literacy: New Perspectives, in Strickland and Morrow (eds), Emergent Literacy: Young Children Learn to Read and Write (pp 1-5).

Newark: DE: International Reading Association

Vygotsky, L. S. (1978). Mind and society: The development of higher mental processes. Cambridge, MA: Harvard University Press. 